\title{
In vitro study of the efficacy of Solanum nigrum against
}

\section{Leishmania major [version 1; peer review: 1 approved with}

\section{reservations, 1 not approved]}

\author{
Christine N. Mutoro (D1, Johnson K. Kinyua1, Joseph K. Ng'ang'a1, \\ Daniel W. Kariuki ${ }^{1}$, Johnstone M. Ingonga ${ }^{2}$, Christopher O. Anjili² \\ ${ }^{1}$ Department of Biochemistry, Jomo Kenyatta University of Agriculture and Technology, Nairobi, Nairobi, 00200, Kenya \\ ${ }^{2}$ Center for Biotechnology Research and Development, Kenya Medical Research Institute, Nairobi, Nairobi, 00200, Kenya
}

V1 First published: 22 Aug 2018, 7:1329
https://doi.org/10.12688/f1000research.15826.1

Latest published: 22 Aug 2018, 7:1329

https://doi.org/10.12688/f1000research.15826.1

\begin{abstract}
Leishmania parasites (Kinetoplastida: Trypanosomatidae) are obligate intracellular parasites of macrophages that causes visceral and cutaneous leishmaniases. Currently, there is inadequate therapeutic interventions to manage this endemic tropical disease, transmitted mainly by phlebotomine sandflies hence there is need to develop affordable and effective therapeutic measures. This study determined the in vitro efficacy of Solanum nigrum methanolic and aqueous plant extracts on Leishmania major parasites. Cytotoxic effects of the extracts were determined using vero cells and reported as percentage viability of the cells. The promastigote parasites of Leishmania major were cultured and grown for 3 days in different concentrations of extracts to determine the MIC and $\mathrm{IC}_{50}$ values. The in vitro antileishmanial efficacy was done on macrophages infected with $L$. major amastigote parasites and then treated with extracts in varying concentrations. The study revealed that all the test extracts had lower toxicity than control drugs, pentostam ( $\mathrm{IC}_{50}=0.092 \mathrm{mg} / \mathrm{ml}$ ) and amphotericin $\mathrm{B}\left(\mathrm{IC}_{50}=0.049 \mathrm{mg} / \mathrm{ml}\right)$. The extracts tended to show a dose dependent cytotoxic effect which corresponded to high vero cells viability as their concentration increased. Methanolic extract of $S$. nigrum from Kisii seemed to be more efficacious in vitro since it knocked out the promastigotes at a lower MIC level $(0.5 \mathrm{mg} / \mathrm{ml})$ when compared to all other extracts whose effective MIC level was $\geq 1$ $\mathrm{mg} / \mathrm{ml}$. High concentrations of the test extracts and control drugs resulted to low infectivity and multiplication of L. major amastigotes. Findings from this study demonstrate that $S$. nigrum extracts have potential antileishmanial activities however; further investigation needs to be done on pure compound isolation, in vivo assays and clinical trials so as to use the promising compounds as effective antileishmanial agents.
\end{abstract}

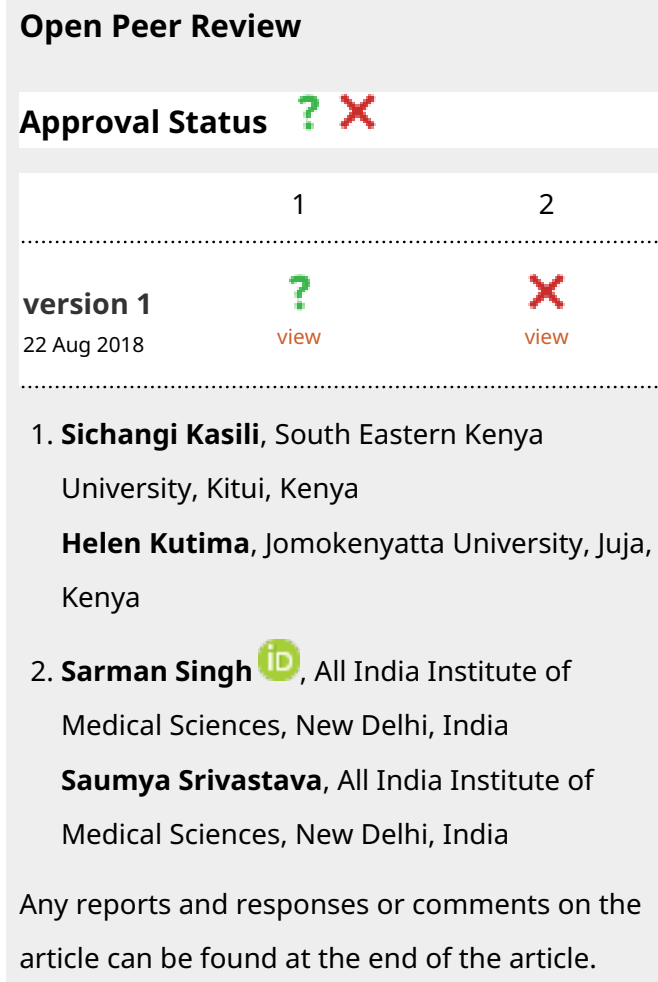

1. Sichangi Kasili, South Eastern Kenya University, Kitui, Kenya

Helen Kutima, Jomokenyatta University, Juja, Kenya

2. Sarman Singh iD, All India Institute of Medical Sciences, New Delhi, India

Saumya Srivastava, All India Institute of Medical Sciences, New Delhi, India

Any reports and responses or comments on the article can be found at the end of the article. 


\section{Keywords}

Leishmaniasis, Leishmania major, Solanum nigrum, Plant extracts,

Toxicity

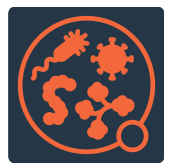

This article is included in the Pathogens

gateway.

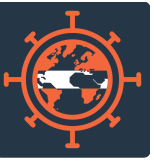

This article is included in the Neglected Tropical

Diseases collection.

Corresponding author: Christine N. Mutoro (cmutoro@jkuat.ac.ke)

Author roles: Mutoro CN: Conceptualization, Data Curation, Formal Analysis, Investigation, Methodology, Project Administration, Resources, Software, Visualization, Writing - Original Draft Preparation, Writing - Review \& Editing; Kinyua JK: Conceptualization, Methodology, Project Administration, Supervision, Writing - Original Draft Preparation, Writing - Review \& Editing; Ng'ang'a JK: Methodology, Project Administration, Supervision, Validation, Writing - Original Draft Preparation, Writing - Review \& Editing; Kariuki DW: Methodology, Project Administration, Supervision, Validation, Writing - Original Draft Preparation, Writing - Review \& Editing; Ingonga JM: Data Curation, Formal Analysis, Investigation, Methodology, Project Administration; Anjili CO: Conceptualization, Methodology, Project Administration, Resources, Supervision, Validation, Writing - Original Draft Preparation, Writing - Review \& Editing Competing interests: No competing interests were disclosed.

Grant information: The author(s) declared that no grants were involved in supporting this work.

Copyright: (c) 2018 Mutoro CN et al. This is an open access article distributed under the terms of the Creative Commons Attribution License, which permits unrestricted use, distribution, and reproduction in any medium, provided the original work is properly cited. Data associated with the article are available under the terms of the Creative Commons Zero "No rights reserved" data waiver (CC0 1.0 Public domain dedication).

How to cite this article: Mutoro CN, Kinyua JK, Ng'ang'a JK et al. In vitro study of the efficacy of Solanum nigrum against Leishmania major [version 1; peer review: 1 approved with reservations, 1 not approved] F1000Research 2018, 7:1329

https://doi.org/10.12688/f1000research.15826.1

First published: 22 Aug 2018, 7:1329 https://doi.org/10.12688/f1000research.15826.1 


\section{Introduction}

Leishmaniasis is a widespread disease caused Leishmania parasites which are transmitted by the sandfly. Desjeux (1998) reported that the disease occurred in different clinical forms, which ranged from cutaneous self-healing lesions to a fatal visceralizing form, and also included the metastasizing mucocutaneous and post-kala-azar dermal leishmaniasis. Leishmaniasis represents an important health and socioeconomic problem in 88 countries around the world, where this disease is endemic according to a study by Dujardin et al. (2008). Despite the death toll and disease burden of leishmaniasis, there is an acute lack of suitable therapies. Treatment of the disease depends on a limited number of drugs with limitations such as high cost, unacceptable host toxicity, poor efficacy, lack of availability, and acquired parasite drug resistance as reported in studies by Barrett \& Fairlamb (1999); Fairlamb (2003) and Stuart et al. (2008). Therefore, the development of cheap, available, effective and less toxic drugs is of paramount importance. Medicinal plants are the best alternative since they possess natural active components that can be effective against parasitic infections or can be used in development of commercial drugs.

Several studies have reported that some plants are effective against Leishmania parasites both in vitro and in vivo. The findings of studies by Kinuthia et al. (2014); Ndeti et al. (2016) and Njau et al. (2016) revealed that plants such as Allium sativum, Callistemon citrinus, Moringa stenopetala and Aloe secundiflora were effective against Leishmania major parasites. A study by Wabwoba et al. (2010) indicated that a combination of M. stenopetala with Allium sativum induced apoptotic effect in Leishmania major promastigotes. Similar results were reported in studies by McClure et al. (1996) where the growth of Leishmania mexicana and Leishmania chagasii were inhibited by A. sativum, and by Khademvatan et al. (2011) where A. sativum extract induced apoptosis in Leishmania major parasites. Schlein et al. (2001) reported that Ricinus communis (Malpighiales: Euphorbiaceae) possessed antileishmanial effects both in Phlebotomus duboscqi (Diptera: Psychodidae), the vector for $L$. major in Israel, and in in vivo in BALB/c mice when used alone, as revealed in a study by Oketch et al. (2006), or in combination with Azadiracta indica (Sapindales: Meliaceae) as indicated by Jumba et al. (2015).

The findings of some studies have shown that Solanaceae family plants have medicinal effects against various parasitic infections. The findings of Laban et al. (2015) showed that Solanum aculeastrum was effective against Leishmania major parasites. Additionally, Mishra et al. (2013) reported that a prenyloxy-naphthoquinone obtained from roots of Plumbago zeylanica (Caryophllales: Plumbaginaceae) has anti-leishmanial activity against Leishmania donovani. There was a significant difference between the $\mathrm{EC}_{50}$ for the isolated compound and miltefosine, the standard drug $(\mathrm{P}<0.001)$ against $L$. donovani promastigotes and amastigotes. Studies on L. major in Kenya by Makwali et al. (2015) have shown that Plumbago capensis possess anti-leishmanial effects. The current study evaluated the in vitro anti-leishmanial activity of Solanum nigrum extracts on L. major parasites.

\section{Methods}

Ethical considerations

The proposal for this research work was submitted to the KEMRI Scientific Steering Committee (SSC), for approval and was given ethical clearance (Number: KEMRI/SSC-2028) on the use of the mice as the animal model by the Ethical Review Committee (ERC). All experimental animals at the end of the experiment were sacrificed by injection of $100 \mu \mathrm{l}$ sodium pentobarbital and disposed of according to the regulations of Animal Care and Use (ACUC) through incineration.

\section{Experimental design}

The in vitro studies were carried out using a comparative study design. Pentostam (Glaxo Operations (UK) Limited, Barnard Castle, UK) and amphotericin B (AmBisome ${ }^{\circledR}$; Gilead, Foster City, CA, USA) were used as the standard drugs to compare their efficacy and toxicity with those of the test extracts. RPMI-1640 and Schneider's Drosophila media (Thermo Fisher Scientific, Waltham, Massachusetts, USA) were used as the control in in vitro experimental chemotherapeutic studies.

\section{Plant collection and preparation of the extracts}

Fresh leaves of Solanum nigrum were collected form Kisii and Bungoma, Kenya, where the plant is abundant. The plants were transferred to the Center of Traditional Medicine and Drug Research (CTMDR) at KEMRI (Nairobi, Kenya) and dried at $25^{\circ} \mathrm{C}$ until they became brittle and attained a constant weight. The dried plants were separately ground using an electric mill (Christy\& Norris Ltd., Chelmford, England) into powder followed by extraction using water and analytical grade methanol. The methanolic extracts were prepared as described by Mekonnen et al. (1999) and Cock (2012). Immediately, $100 \mathrm{~g}$ of ground plant material was soaked in $500 \mathrm{ml}$ of analytical grade methanol for $72 \mathrm{~h}$ at room temperature with gentle shaking. The mixture was filtered using Whatman No.1 filter papers and concentrated using a rotary evaporator to obtain dry methanolic extracts. The extracts were coded as A and B for methanolic extracts of $S$. nigrum (Bungoma) and S. nigrum (Kisii), respectively. The aqueous extracts were prepared as described by Delahaye et al. (2009). Briefly, $100 \mathrm{~g}$ of the dried ground plant material in $600 \mathrm{ml}$ of distilled water was placed in a water bath at $70^{\circ} \mathrm{C}$ for $1.5 \mathrm{~h}$. The mixture was filtered using Whatman No.1 filter papers and then the filtrate frozen, dried and weighed. The extracts were coded as C and D for $S$. nigrum (Kisii) and S. nigrum (Bungoma), respectively. The extracts were then stored at $4^{\circ} \mathrm{C}$ until required for bioassays.

\section{Mice and Leishmania parasites}

A total of four 8-week-old male inbred BALB/c mice with weights that ranged between 25 and $29 \mathrm{~g}$ were obtained from KEMRI. There were eight BALB/c mice per cage in the animal house kept at $23-25^{\circ} \mathrm{C}$ under a $12 / 12 \mathrm{~h}$ light/dark cycle and were fed on standard diet in the form of mouse pellets and given tap water ad libitum. The mice were handled in accordance with the regulations set by the Animal Care and Use Committee at KEMRI. The mice were used for extraction of peritoneal macrophages that were used for anti-amastigote assay. 
The Leishmania major strain (IDUB/KE/94=NLB-144) which was originally isolated in 1983 from a female Phlebotomus dubosqi collected from Marigat, Baringo County in Kenya were used. The parasites were grown to stationary phase at $25^{\circ} \mathrm{C}$ in Schneider's Drosophila medium supplemented with $20 \%$ heat-inactivated fetal bovine serum (FBS) Hyclone $^{\circledR}$ USA), $100 \mathrm{U} / \mathrm{ml}$ penicillin and $500 \mu \mathrm{g} / \mathrm{ml}$ streptomycin (Hendricks \& Wright, 1979), and $250 \mu \mathrm{g} / \mathrm{ml} \mathrm{5-fluorocytosine} \mathrm{arabinoside}$ (Kimber et al., 1981). The stationary-phase metacyclic stage promastigotes were then harvested by centrifugation at $1500 \mathrm{~g}$ for $15 \mathrm{~min}$ at $4{ }^{\circ} \mathrm{C}$. The metacyclic promastigotes were then used for the in vitro assays.

\section{Preparation of the stock solutions of test extracts}

Stock solutions of the crude plant extracts were made in Schneider's Drosophila culture medium for anti-leishmanial assays and filtered through $0.22-\mu \mathrm{m}$ filter flasks in a laminar flow hood (Biological Safety Cabinet). The stock solutions were then stored at $4{ }^{\circ} \mathrm{C}$ and retrieved later for both in vitro bioassays.

\section{Cytotoxicity assay using Vero cells to determine $\mathrm{IC}_{50}$} values

This assay was used to test the cytotoxicity of individual extracts against Vero cells (Thermo Fischer Scientific, Waltham, Massachusetts, USA) and the results were presented as $\mathrm{IC}_{50}$ values. The assay was carried out as described by Wabwoba et al. (2010). Vero cells were grown in minimum essential medium (MEM) (ATCC® $30-2003^{\mathrm{TM}}$ ) supplemented with $10 \% \mathrm{FBS}$, penicillin $(100 \mathrm{IU} / \mathrm{ml})$ and streptomycin $(100 \mu \mathrm{g} / \mathrm{ml})$ in $25 \mathrm{ml}$ cell culture flasks incubated at $37^{\circ} \mathrm{C}$ in a humidified $5 \% \mathrm{CO}_{2}$ for $24 \mathrm{~h}$. The Vero cells were harvested by trypsinization and pooled in 50-ml centrifuge tubes from which $100 \mu \mathrm{l}$ of cell suspension was moved into two wells of rows A-H in a 96-well flatbottomed microtiter plate at a concentration of $1 \times 10^{6}$ cells per $\mathrm{ml}$ of the culture medium per well and incubated at $37^{\circ} \mathrm{C}$ in $5 \% \mathrm{CO}_{2}$. The MEM was gently aspirated off and $150 \mu \mathrm{l}$ of the test extracts (A, B, C and D) were added at concentrations of $1000 \mu \mathrm{g} / \mathrm{ml}, 500 \mu \mathrm{g} / \mathrm{ml}, 250 \mu \mathrm{g} / \mathrm{ml}, 125 \mu \mathrm{g} / \mathrm{ml}, 62.5 \mu \mathrm{g} / \mathrm{ml}$ and $31.25 \mu \mathrm{g} / \mathrm{ml}$ in the micro titer plates. The plates containing the Vero cells and test extracts were further incubated at $37^{\circ} \mathrm{C}$ for $48 \mathrm{~h}$ in a humidified $5 \% \quad \mathrm{CO}_{2}$ atmosphere. The controls wells comprised of Vero cells and medium while the blank wells had medium alone. A total of $10 \mu \mathrm{l}$ of (3-(4, 5-dimethylthiazol-2-yl)-2, 5-diphenyltetrazolium bromide (MTT) reagent were added into each well and incubated further for 2-4 h until a purple precipitate (formazan) was visible under the microscope. The media together with MTT reagent was gently be aspirated off, after which $100 \mu$ of dimethyl sulfoxide (DMSO) was added, and vigorously shaken for 5 minutes in order to dissolve formazan. The absorbance (optical density) was measured for each well plate using a microtiter plate reader at wavelength of $570 \mathrm{~nm}$. The $\mathrm{IC}_{50}$ values of the extracts were determined automatically using the Chemosen program 2.

\section{Evaluation of minimum inhibitory concentration (MIC)}

The MICs were determined as described by Wabwoba et al. (2010). Briefly, the L. major metacyclic promastigotes at concentration of $1 \times 10^{6}$ promastigotes per $\mathrm{ml}$ of the culture medium were treated with individual methanolic test extracts $\mathrm{A}$ and $\mathrm{B}$ whose concentrations were $2000 \mu \mathrm{g} / \mathrm{ml}, 1000 \mu \mathrm{g} / \mathrm{ml}, 500 \mu \mathrm{g} / \mathrm{ml}$ and $250 \mu \mathrm{g} / \mathrm{ml}$. These test procedures were repeated for aqueous extracts $\mathrm{C}$ and $\mathrm{D}$. The lowest concentration of the individual test extracts in which no live promastigotes were observed was the MIC.

\section{Evaluation of $\mathrm{IC}_{50}$ and antipromastigote assay}

Metacyclic promastigotes at a concentration of $1 \times 10^{6}$ promastigotes per $\mathrm{ml}$ of the culture medium were grown for $48 \mathrm{~h}$ in 24-well microtiter plates at $25^{\circ} \mathrm{C}$. Aliquots of the promastigotes were transferred into 96 well microtiter plates and incubated further at $27^{\circ} \mathrm{C}$ for $24 \mathrm{~h}$ after which $200 \mu \mathrm{l}$ of the highest concentrations $(2 \mathrm{mg} / \mathrm{ml})$ of the individual test extracts were added before serial dilutions of $2.0 \times 10^{3}, 1.0 \times 10^{3}, 5.0 \times 10^{2}$, $2.5 \times 10^{2}, 1.25 \times 10^{2}$, and $6.25 \times 10^{1}$ were carried out. The control wells contained L. major promastigotes in culture medium alone whereas the blank wells had the culture medium alone. The plates were incubated further at $27^{\circ} \mathrm{C}$ for $48 \mathrm{~h}$ and $10 \mu \mathrm{l}$ of MTT reagent was into each well and incubated further for $4 \mathrm{~h}$. The medium and MTT reagent were aspirated off the wells. Next, in each well, $100 \mu$ l of DMSO was added and the plates shaken for 5 minutes. Absorbances were read at $562 \mathrm{~nm}$ using a microtiter reader. The absorbance readings were used to generate $\mathrm{IC}_{50}$ values for the different plant extracts using the Chemosen program v2.

Survival of L. major promastigotes was stratified as follows: ,$++++ 75-100 \%$ survival compared with control; +++, 50-<75\% survival compared with control;,$++ 25-<50 \%$ survival compared with control;,$+<25 \%$ survival compared with control; -, absence of live promastigotes.

\section{Anti-amastigote assay}

The anti-amastigote assay was carried out as described by Delorenzi et al. (2001). The peritoneal macrophages were obtained from four clean BALB/c mice. The mice were anaesthetized using $100 \mu \mathrm{l}$ pentobarbital sodium (Sagatal $\left.{ }^{\circledR}\right)$. The body surface of the mouse was disinfected with $70 \%$ ethanol after which it was opened dorso-ventrally to expose the peritoneum. A total of $10 \mu \mathrm{l}$ sterile cold PBS was injected into the peritoneum. After injection, the peritoneum was gently massaged for 2 min to dislodge and release macrophages into the PBS. The peritoneal macrophages were then be harvested by withdrawing the PBS. The PBS containing the macrophages was washed through centrifugation at $2,000 \mathrm{~g}$ for $10 \mathrm{~min}$ and the pellet obtained was re-suspended in RPMI-1640 culture medium. The macrophages were adsorbed in 24-well plates for $4 \mathrm{~h}$ at $37^{\circ} \mathrm{C}$ in $5 \% \mathrm{CO}_{2}$. Non-adherent cells were washed away with cold sterile PBS and the adherent macrophages were incubated overnight in RPMI-1640 culture medium. Adherent macrophages were then infected with $L$. major promastigotes and were further incubated at $37^{\circ} \mathrm{C}$ in $5 \%$ for $4 \mathrm{~h}$, after which they were washed with sterile PBS to remove the free promastigotes, which were not engulfed by the macrophages. This was followed by incubation of the preparation for $24 \mathrm{~h}$ in RPMI-1640 culture medium.

Pentostam and liposomal amphotericin $\mathrm{B}$ at concentrations of $125 \mu \mathrm{g} / \mathrm{ml}, 250 \mu \mathrm{g} / \mathrm{ml}$ and $500 \mu \mathrm{g} / \mathrm{ml}$ were used as positive 
control drugs to compare the parasite inhibition with that by plant extracts. The medium and test extracts or drug was replenished daily for 3 days. After 5 days, the macrophages were washed with sterile PBS at $37^{\circ} \mathrm{C}$, fixed in methanol and stained with $10 \%$ Giemsa. The number of amastigotes was determined by counting at least 100 macrophages in duplicate cultures, and the count was expressed as infection rate (IR) and multiplication index (MI) as described by Berman \& Lee (1984) in the calculations below:

IR $(\%)=$ Number of infected macrophages per 100 macrophages

$\operatorname{MI}(\%)=\frac{\text { Number of amastigotes in exp erimental culture per } 100 \text { macrophages }}{\text { Number of amastigotes in control culture per } 100 \text { macrophages }} \times 100$

\section{Statistical analysis}

The $\mathrm{IC}_{50}$ values were determined using Chemosen program v2. Data for infection rates and multiplication indices were saved as percentages and then were analyzed using SPSS 13.0 programme. The results were expressed as mean values \pm standard deviation (SD). Statistical analysis were done using one way ANOVA and Tukey's post hoc test and $p$ values $<0.05$ were considered significant.

\section{Results}

\section{Cytotoxicity assays using Vero cells}

Generally, all the test extracts studied were less toxic (i.e. higher $\mathrm{IC}_{50}$ values) to Vero cells when compared to the control drugs, pentostam $(0.03 \mathrm{mg} / \mathrm{ml})$ and amphotericin B $(0.01 \mathrm{mg} / \mathrm{ml})$ (Table 1).

The methanolic and aqueous extracts tended to show a dosedependent cytotoxic effect which corresponded to low $\mathrm{IC}_{50}$ values as their concentration increased. Methanolic extracts of S.nigrum from Bungoma and Kisii had $\mathrm{IC}_{50}$ values of $0.57 \mathrm{mg} / \mathrm{ml}$ and $0.50 \mathrm{mg} / \mathrm{ml}$ while those their aqueous counterparts were $0.76 \mathrm{mg} / \mathrm{ml}$ and $0.64 \mathrm{mg} / \mathrm{ml}$ (Table 1 ).
The survival of L. major promastigotes after exposure to extracts and controls

Preliminary studies involved exposure of the L. major promastigotes to extracts and control drugs at varying concentrations in vitro. The L. major parasites cultured in Schneider's Drosophila medium were taken as the negative control because the parasites continued to multiply. Both pentostam and amphotericin B used were able to inhibit the Leishmania major promastigotes growth at an MIC of $31.25 \mu \mathrm{g} / \mathrm{ml}$. The Schneider's Drosophila medium, on the other hand, led to maximum survival of L. major promastigotes (++++) (Table 2).

Both aqueous extracts of $S$. nigrum from Bungoma and Kisii (C and D) inhibited the survival of Leishmania major promastigotes at an MIC of $2000 \mu \mathrm{g} / \mathrm{ml}$. S. nigrum methanolic extracts from Bungoma (A) lowered L. major parasites at a concentration of $1000 \mu \mathrm{g} / \mathrm{ml}$, while that from Kisii (B) inhibited L. major multiplication at an MIC of $500 \mu \mathrm{g} / \mathrm{ml}$.

The concentrations of the extracts that were effective against L. major promastigotes in vitro were high $(>0.5 \mathrm{mg} / \mathrm{ml})$ compared to those of the standard drugs $(0.03125 \mathrm{mg} / \mathrm{ml})$. The efficacy of methanolic extracts was better than their respective aqueous counter parts (Table 2).

Table 1. The IC $\mathrm{C}_{50}$ values showing the effects of the extracts and controls on Vero cells. The initial concentration of the test extracts was $1000 \mu \mathrm{g} / \mathrm{ml}$ while that of control drugs was $500 \mu \mathrm{g} / \mathrm{ml}$ before serial dilution

\begin{tabular}{|l|l|l|}
\hline Code & Test extracts and drugs & $\mathbf{I C}_{50}, \mathbf{m g} / \mathbf{m l}$ \\
\hline A & S. nigrum (Bungoma) methanolic extract & 0.57 \\
\hline B & S. nigrum (Kisii) methanolic extract & 0.50 \\
\hline C & S. nigrum (Kisii) aqueous extract & 0.64 \\
\hline D & S. nigrum (Bungoma) aqueous extract & 0.76 \\
\hline Pento & Pentostam & 0.03 \\
\hline Ampho B & Amphotericin B & 0.01 \\
\hline
\end{tabular}

Table 2. Survival of $L$. major promastigotes in varying concentrations of the plant extracts as observed under a light microscope.

\begin{tabular}{|c|c|c|c|c|c|c|}
\hline \multirow[t]{2}{*}{ Test extracts and drugs } & \multirow[t]{2}{*}{ Extraction type } & \multirow[t]{2}{*}{ Code } & \multicolumn{4}{|c|}{ Concentration of the extracts $(\mu \mathrm{g} / \mathrm{ml})$} \\
\hline & & & 2000 & 1000 & 500 & 250 \\
\hline S. nigrum (Bungoma) & Methanolic & A & - & + & ++ & ++++ \\
\hline S. nigrum (Kisii) & Methanolic & B & - & - & - & ++ \\
\hline S. nigrum (Kisii) & Aqueous & C & + & +++ & ++++ & ++++ \\
\hline S. nigrum (Bungoma) & Aqueous & $\mathrm{D}$ & + & +++ & ++++ & ++++ \\
\hline \multirow{2}{*}{\multicolumn{3}{|c|}{ Control drug }} & \multicolumn{4}{|c|}{ Standard drug concentration, $\mu \mathrm{g} / \mathrm{ml}$} \\
\hline & & & 125 & 62.5 & 31.25 & 15.625 \\
\hline \multicolumn{3}{|l|}{ Pentostam } & - & - & - & ++ \\
\hline \multicolumn{3}{|l|}{ Amphotericin B } & - & - & - & + \\
\hline \multicolumn{3}{|c|}{ Schneider's Drosophila Medium } & ++++ & ++++ & +++++ & ++++ \\
\hline
\end{tabular}

,$++++ 75-100 \%$ survival compared with control;,$+++ 50-<75 \%$ survival compared with control;,$++ 25-<50 \%$ survival compared with control; +, <25\% survival compared with control; -, absence of live promastigotes. 
Minimum inhibitory concentrations $(\mathrm{MIC})$ and $\mathrm{IC}_{50}$ values of the extracts on L. major promastigotes

The MICs of $S$. nigrum from Bungoma (A) and $S$. nigrum from Kisii (B) methanolic extracts were $1000 \mu \mathrm{g} / \mathrm{ml}$ and $500 \mu \mathrm{g} / \mathrm{ml}$, respectively. Both aqueous extracts of $S$. nigrum from Kisii (C) and S. nigrum from Bungoma (D) had MIC values of $2000 \mu \mathrm{g} / \mathrm{ml}$. The standard drugs had lower MICs $(31.25 \mu \mathrm{g} / \mathrm{ml})$ against $L$. major promastigotes compared to the test extracts. Schneider's Drosophila medium, which was the negative control, supported maximum survival of Leishmania major promastigotes (Table 3).

$\mathrm{IC}_{50}$ values determined indicated the effectiveness of the test extracts or the controls in inhibiting the promastigotes by $50 \%$. Pentostam and amphotericin B had $\mathrm{IC}_{50}$ values of $0.08 \mathrm{mg} / \mathrm{ml}$ and $0.04 \mathrm{mg} / \mathrm{ml}$, respectively, while $S$. nigrum from Bungoma (A) and S. nigrum from Kisii (B) methanolic extracts had $\mathrm{IC}_{50}$ values of $1.81 \mathrm{mg} / \mathrm{ml}$ and $1.28 \mathrm{mg} / \mathrm{ml}$, respectively. Similarly, aqueous extracts of $S$. nigrum from Kisii (C) and S. nigrum from Bungoma (D) had $\mathrm{IC}_{50}$ values of $1.18 \mathrm{mg} / \mathrm{ml}$ and $1.84 \mathrm{mg} / \mathrm{ml}$, respectively. Based on the $\mathrm{IC}_{50}$ values, the aqueous extract of S. nigrum from Kisii (C) was the most effective of the extracts (Table 3 ).

For extracts that shared the same MICs, higher $\mathrm{IC}_{50}$ values tended to correspond to increased in vitro survival of promastigotes of Leishmania. The methanolic extract of S. nigrum from Kisii seemed to be more efficacious in vitro since it knocked out the promastigotes at a lower MIC level $(0.5 \mathrm{mg} / \mathrm{ml})$ when compared to all other extracts whose effective MIC level was $\geq 1 \mathrm{mg} / \mathrm{ml}$ (Table 3 ).

\section{Anti-amastigote assay (macrophage assay)}

RPMI-1640 medium with no drug had an infection rate of 96.7\% (Table 4), which implied that it supported maximum growth of Leishmania major amastigotes in peritoneal macrophages (Figure 1). The leishmaniasis drugs pentostam and liposomal amphotericin B inhibited the in vitro survival of L. major amastigotes, corresponding to low infection rates of $26.3 \%$ and $21.0 \%$, respectively, at a concentration of $50 \mu \mathrm{g} / \mathrm{ml}$ (Table 4).

At a concentration of $125 \mu \mathrm{g} / \mathrm{ml}$, the methanolic extracts of S. nigrum from Bungoma (A) and S. nigrum from Kisii (B) had infection rates of $71.0 \pm 2.3 \%$ and $68.0 \pm 2.7 \%$, respectively. Similarly, the infection rates of aqueous extracts, S. nigrum from Kisii (C) and S. nigrum from Bungoma (D) were $78.0 \pm 2.5 \%$ and $85.3 \pm 1.2 \%$ (Table 4 ).

The methanolic extract of S. nigrum from Kisii (B) inhibited the survival of $L$. major amastigotes better than the other extracts in all the concentrations studied (Figure 2). High concentrations of the test extracts and control drugs resulted in low IRs and MIs of L. major amastigotes. The efficacies were dosedependent. The difference between the IRs of test extracts and the control drugs were statistically significant $(\mathrm{P}<0.05)$.

When the MIs of amastigotes in peritoneal macrophages treated with $125 \mu \mathrm{g} / \mathrm{ml}$ of methanolic test extracts (A and B) were compared with those treated with $50 \mu \mathrm{g} / \mathrm{ml}$ of amphotericin or pentostam, using one-way ANOVA, there was a statistically significant difference $(\mathrm{P}<0.001)$. A Tukey post hoc test revealed that the MI of methanolic extracts of $S$. nigrum from Kisii (A and B) at $500 \mu \mathrm{g} / \mathrm{ml}$ were statistically significant from that of pentostam and amphotericin $\mathrm{B}(\mathrm{P}=0.001)$.

When the infection rates of methanolic extracts of $500 \mu \mathrm{g} / \mathrm{ml}$ $\mathrm{A}$ and $\mathrm{B}$ were compared with those of amphotericin B using Tukey's post hoc test, the difference in each case was statistically significant, $(\mathrm{P}<0.001$ and $\mathrm{P}=0.001$, respectively $)$. Comparisons of the IRs for extracts $\mathrm{C}$ and $\mathrm{D}$ with those of amphotericin B or pentostam followed a similar trend, where Tukey's post hoc test indicated a significant difference $(\mathrm{P}<0.05)$ for each comparison. The MIs of pentostam and amphotericin $\mathrm{B}$ were not statistically different $(\mathrm{P} \geq 0.05)$ at a concentration of $25 \mu \mathrm{g} / \mathrm{ml}$.

Dataset 1. Raw data for absorbance values from MTT assay and subsequent calculation of IC50 values on Vero cells for extracts of Solanum nigrum from Kisii and controls

https://doi.org/10.5256/f1000research.15826.d214921

For sorted raw absorbance data, columns 3, 6, 9 and 12 contain untreated cells; wells A1, A2, A4, A5, A7, A8, A10, A11, B1, B2, B4, $B 5, B 7, B 8, B 10$ and B11 contain medium only. Rows $\mathrm{C}-\mathrm{H}$ contain indicated test samples, with extract concentrations of $31.25,62.5$, $125,250 \mu \mathrm{g} / \mathrm{ml}, 500$ and $1000 \mu \mathrm{g} / \mathrm{ml}$, respectively, and control drug concentrations of $16.125,31.25,62.5,125,250$ and $500 \mu \mathrm{g} / \mathrm{ml}$, respectively.

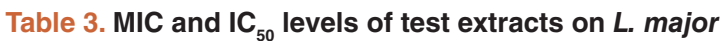

promastigotes. The extracts concentration ranged from $2000 \mu \mathrm{g} / \mathrm{ml}$ to $250 \mu \mathrm{g} / \mathrm{ml}$ for MIC and $62.5 \mu \mathrm{g} / \mathrm{ml}$ for $\mathrm{IC}_{50}$ determination, while the concentration of the positive controls ranged from $125 \mu \mathrm{g} / \mathrm{ml}$ to $15.625 \mu \mathrm{g} / \mathrm{ml}$ for $\mathrm{MIC}$ and $500 \mu \mathrm{g} / \mathrm{ml}$ to $15.625 \mu \mathrm{g} / \mathrm{ml}$ for $\mathrm{IC}_{50}$ determination.

\begin{tabular}{|l|l|l|l|}
\hline Code & Test extracts and drugs & MIC, $\mathbf{~ m g / m I}$ & $\mathbf{I C}_{\mathbf{5 0}}, \mathbf{m g} / \mathbf{m I}$ \\
\hline A & Methanolic S. nigrum (Bungoma) & 1 & 1.81 \\
\hline B & Methanolic S. nigrum (Kisii) & 0.5 & 1.28 \\
\hline C & Aqueous S. nigrum (Kisii) & 2 & 1.18 \\
\hline D & Aqueous S. nigrum (Bungoma) & 2 & 1.84 \\
\hline Pento & Pentostam & 0.03125 & 0.08 \\
\hline Amph B & Amphotericin B & 0.03125 & 0.04 \\
\hline
\end{tabular}


Table 4. Infectivity of $L$. major amastigotes in macrophages after treatment with various test extracts and standard drugs.

\begin{tabular}{|c|c|c|c|}
\hline Code & Concentration, $\mu \mathrm{g} / \mathrm{ml}$ & Infection rate, $\%$ & Multiplication index, \% \\
\hline \multirow[t]{3}{*}{ A } & 500 & $55.6 \pm 2.7$ & $60.3 \pm 3.4$ \\
\hline & 250 & $63.6 \pm 4.6$ & $65.5 \pm 5.1$ \\
\hline & 125 & $71.0 \pm 2.3$ & $71.8 \pm 0.8$ \\
\hline \multirow[t]{3}{*}{ B } & 500 & $51.6 \pm 4.3$ & $59.2 \pm 2.5$ \\
\hline & 250 & $59.0 \pm 5.0$ & $67.7 \pm 3.6$ \\
\hline & 125 & $68.0 \pm 2.6$ & $69.3 \pm 2.5$ \\
\hline \multirow[t]{3}{*}{ C } & 500 & $69.6 \pm 4.1$ & $67.1 \pm 3.2$ \\
\hline & 250 & $74.6 \pm 5.0$ & $74.1 \pm 3.8$ \\
\hline & 125 & $78.0 \pm 2.5$ & $83.3 \pm 2.9$ \\
\hline \multirow[t]{3}{*}{ D } & 500 & $76.6 \pm 4.1$ & $79.7 \pm 3.0$ \\
\hline & 250 & $78.6 \pm 4.4$ & $82.3 \pm 2.5$ \\
\hline & 125 & $85.3 \pm 1.2$ & $89.2 \pm 0.5$ \\
\hline \multirow[t]{3}{*}{ Pentostam } & 100 & $21.3 \pm 2.3$ & $21.8 \pm 3.0$ \\
\hline & 50 & $26.3 \pm 1.2$ & $25.7 \pm 3.7$ \\
\hline & 25 & $26.7 \pm 2.3$ & $34.4 \pm 2.8$ \\
\hline \multirow[t]{3}{*}{ Amphotericin B } & 100 & $19.0 \pm 2.3$ & $18.8 \pm 2.2$ \\
\hline & 50 & $21.0 \pm 2.1$ & $27.2 \pm 2.5$ \\
\hline & 25 & $22.0 \pm 1.5$ & $33.7 \pm 1.8$ \\
\hline RPMI-1640 & \multicolumn{2}{|l|}{$96.67 \pm 0.9$} & 100.0 \\
\hline
\end{tabular}

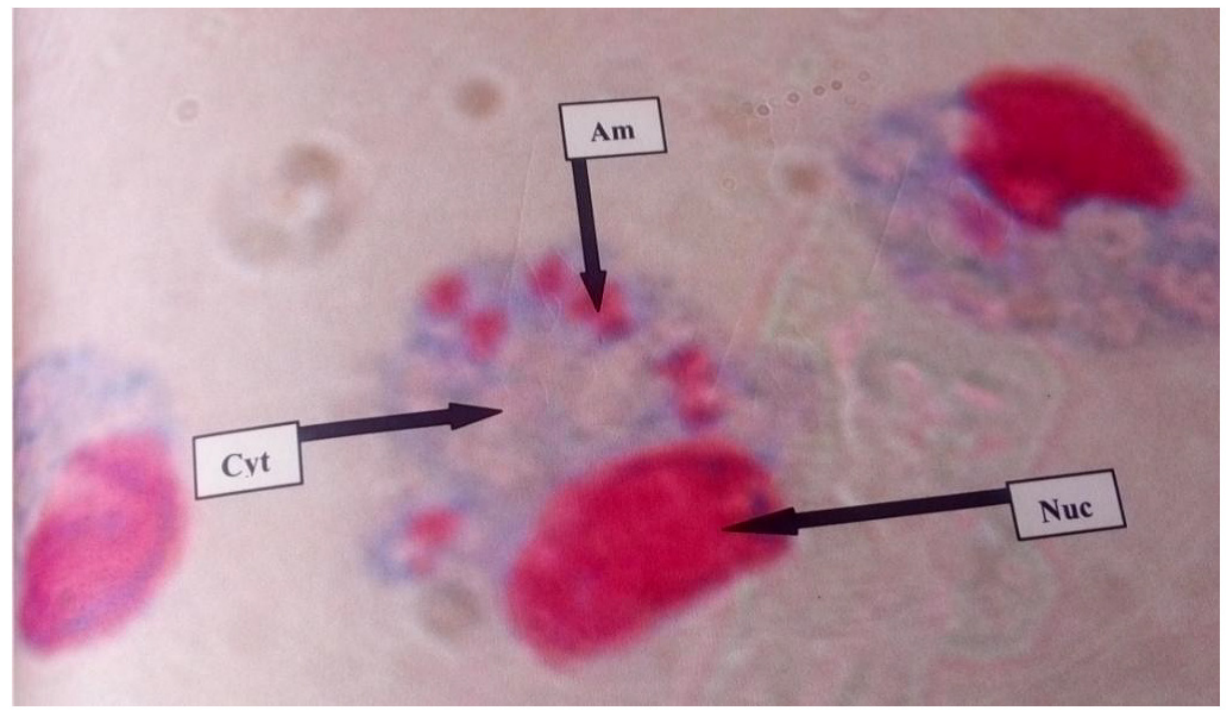

Figure 1. Showing a BALB/c mice peritoneal macrophage having engulfed $L$. major amastigotes at 5 days post infection in RPMI-1640 medium culture. $\mathrm{Am}=$ amastigote, $\mathrm{NuC}=$ Nucleus, and Cyt= Cytoplasm. 


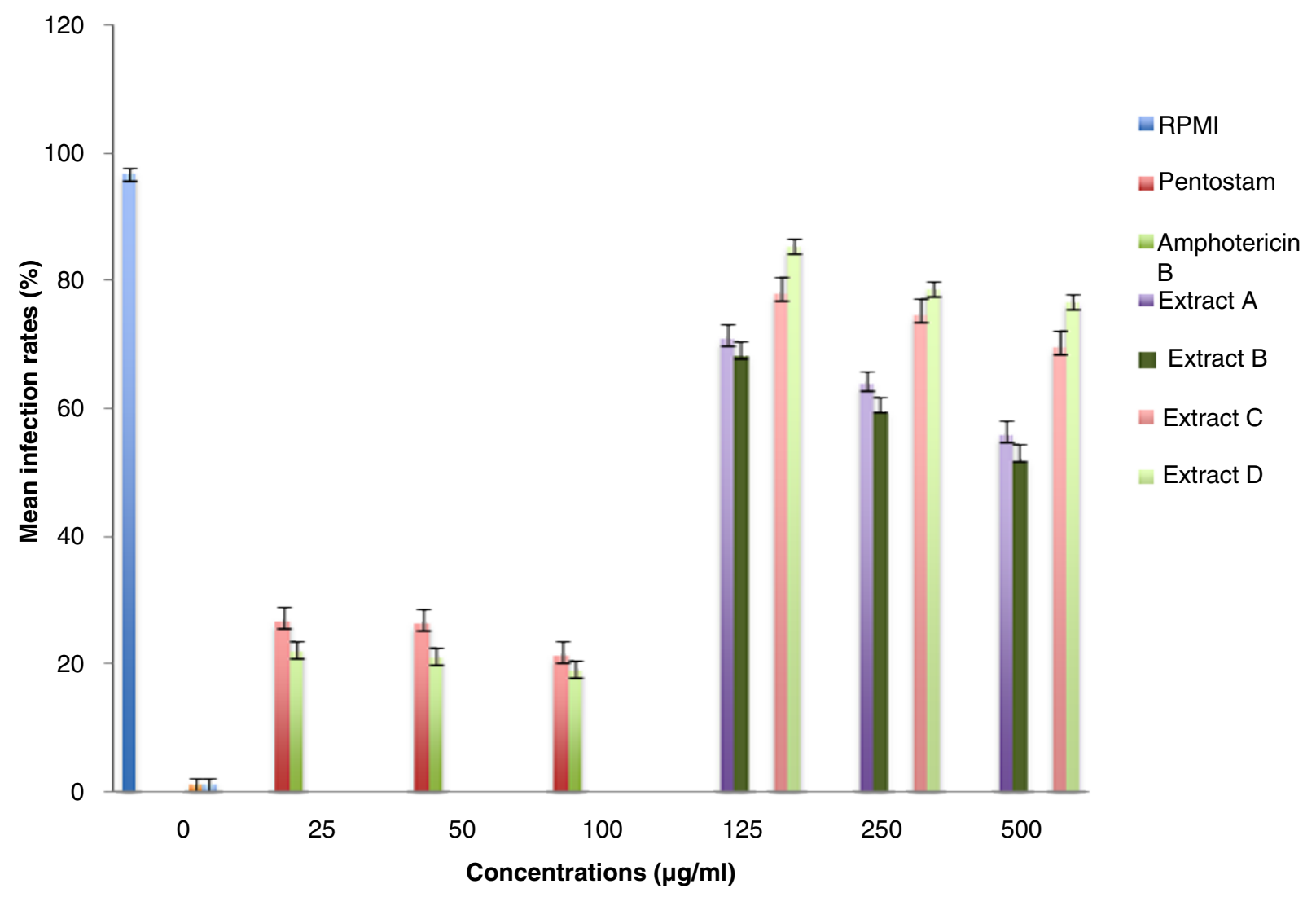

Figure 2. The in vitro activities of the test extracts and controls against $L$. major amastigotes in BALB/c peritoneal macrophages.

Dataset 2. Raw data for absorbance values from MTT assay and subsequent calculation of IC50 values (on Vero cells) for extracts of Solanum nigrum from Bungoma

https://doi.org/10.5256/f1000research.15826.d214922

For sorted raw absorbance data, columns 3, 6, 9 and 12 contain untreated cells; wells A1, A2, A4, A5, A7, A8, A10, A11, B1, B2, B4, $\mathrm{B} 5, \mathrm{~B} 7, \mathrm{~B} 8, \mathrm{~B} 10$ and B11 contain medium only. Rows $\mathrm{C}-\mathrm{H}$ contain test samples, with extract concentrations of $31.25,62.5,125,250$, 500 and $1000 \mu \mathrm{g} / \mathrm{ml}$, respectively.

Dataset 3. Raw data for absorbance values from MTT assay and subsequent calculation of IC50 values (on promastigotes) for extracts of Solanum nigrum from Kisii and controls

https://doi.org/10.5256/f1000research.15826.d214923

For sorted raw absorbance data, columns 3, 6, 9 and 12 contain untreated cells; wells A1, A2, A4, A5, A7, A8, A10, A11, B1, B2, B4, B5, B7, B8, B10 and B11 contain medium only. Rows C-H contain test samples, with extract concentrations of $62.5,125,250$, 500,1000 and $2000 \mu \mathrm{g} / \mathrm{ml}$, respectively $\mathrm{C}$ to $\mathrm{H}$ for extract samples and $16.125,31.25,62.5,125,250$ and $500 \mu \mathrm{g} / \mathrm{ml}$, respectively, for standard drugs.
Dataset 4. Raw data for absorbance values from MTT assay and subsequent calculation of IC50 values (on promastigotes) for extracts of Solanum nigrum from Bungoma

https://doi.org/10.5256/f1000research.15826.d214924

For sorted raw absorbance data, columns $3,6,9$ and 12 contain untreated cells; wells A1, A2, A4, A5, A7, A8, A10, A11, B1, B2, B4, B5, B7, B8, B10 and B11 contain medium only. Rows C-H contain test samples, with extract concentrations of $62.5,125,250,500$, 1000 and $2000 \mu \mathrm{g} / \mathrm{ml}$, respectively.

Dataset 5. Anti-amastigote (macrophage) assays

https://doi.org/10.5256/f1000research.15826.d214929

\section{Discussion}

This study has shown that $S$. nigrum has anti-leishmanial activity against Leishmania parasites. The results indicated that the plant extracts of $S$. nigrum obtained from Kisii and Bungoma have the potential to inhibit $L$. major promastigotes in vitro. The current study further established that the concentrations 
of the extracts that were effective (MIC) against $L$. major promastigotes in vitro were relatively high $(>0.5 \mathrm{mg} / \mathrm{ml})$, as compared to those of pentostam and amphotericin $\mathrm{B}$, which both inhibited the promastigotes at $0.03125 \mathrm{mg} / \mathrm{ml}$. The efficacy of methanolic extracts was better than their respective aqueous counterparts. Schneider's Drosophila medium was used as a negative control and supported maximum survival of the L. major promastigotes in vitro. This was expected because this medium supports the growth of Leishmania promastigotes and amastigotes, as described by Hendricks \& Wright, 1979. The efficacy of test extracts was higher than that of Schneider's Drosophila medium. The slight differences that have been noted between the two allopatric plants could be due to factors such as difference in the presence and composition of the phytochemicals; a study by Aritho et al. (2017) on T. vogelii also revealed such differences.

A study by Son et al. (2003) showed that extracts from S. nigrum leaves had the potential to be used in treatment of tumors, especially liver cancer, and also used for treatment of lung cancer, bladder and gastric carcinoma as indicated by studies done by Mueller et al. (2005) and Ashwani et al. (2012). Additionally, studies by Jain et al. (2011) and Ashwani et al. (2012) revealed that methanol crude extracts obtained from Solanum nigrum possessed antioxidant activity due to its DPPH radical scavenging activity.

Studies by Estevez et al. (2007); Filho et al. (2013); Hubert et al. (2014); and Shen et al. (2012) revealed that some species of Solanum had antileishmanial activity. Findings from the study by Estevez et al. (2007) showed that the extracts of S. stramonifolium had activity against L.amazonensis amastigotes. This activity was attributed to steroid derivatives which include cilistol A and steroidal alkaloids, which form the main components in Solanum species (Abreu Miranda et al., 2013; Filho et al., 2013).

Cytotoxic assays using Vero cells showed that the test extracts were less toxic compared to the standard antileishmanial drugs. Generally, the increase in the dose of the extracts led to a higher cytotoxic effect on $L$. major promastigotes, resulting in inhibition of the growth of the parasites. Many drugs used for treatment of leishmniasis are highly toxic (Santos et al., 2008) and this study confirmed that pentostam and amphotericin B are toxic compared with the extracts tested. The continued use of the contemporary leishmaniasis drugs despite their toxicity is mainly due to lack of an alternative. The use of herbal medicine can be a cheaper and available alternative. The aqueous extracts of both $S$. nigrum from Bungoma and Kisii $\left(\mathrm{IC}_{50}, 0.76 \mathrm{mg} / \mathrm{ml}\right.$ and $0.64 \mathrm{mg} / \mathrm{ml}$, respectively) were less toxic than methanolic extracts $\left(\mathrm{IC}_{50}\right.$ of $0.57 \mathrm{mg} / \mathrm{ml}$ and $0.50 \mathrm{mg} / \mathrm{ml}$, respectively).

The lower the toxicity of the test extracts, the higher the viability of Vero cells after exposure to extracts and vice versa. According to Das et al. (2007) the Solanaceae family plants have been reported to be poisonous both to humans and livestock. Their toxicity has been attributed to the presence of tropane alkaloids, which when ingested in large quantities, causes anticholinergic effects. Another study by Glossman-Mitnik (2007) reported that the toxicity of S. nigrum which is edible is due to solanine, a glycoalkaloid which causes toxicity as the concentration increases.

The $S$. nigrum from Bungoma (A) and S. nigrum from Kisii (B) methanolic crude extracts had infection rates of $71.0 \pm 2.3 \%$ and $68.0 \pm 2.6 \%$, respectively, at a concentration of $125 \mu \mathrm{g} / \mathrm{ml}$. Similarly, the infection rates of aqueous extracts, S. nigrum from Kisii (C) and S. nigrum from Bungoma (D) were 78.0 $2.5 \%$ and $85.3 \pm 1.2 \%$, respectively. In comparison, the leishmaniasis drugs, pentostam and liposomal amphotericin B inhibited the in vitro survival of $L$. major amastigotes more effectively and this corresponded to low infection rates of $26.3 \%$ and $21 \%$, respectively, at a concentration of $50 \mu \mathrm{g} / \mathrm{ml}$. There was a significant difference between the efficacy of the test extracts and that of the Leishmania drugs $(\mathrm{P}<0.05)$. This observation indicates that $S$. nigrum extracts which are known for their antimicrobial and antifungal potential (Abbas et al., 2014; Musto, 2014). When the test extracts were compared with the controls, IR of macrophages by $L$. major amastigotes in plain RPMI-1640 medium (negative control) was $96.7 \pm 0.9 \%$. This agrees with Berman \& Wyler (1980) who observed that the amastigotes of Leishmania tropica and Leishmania donovani in peritoneal macrophages multiplied about three fold in six days when grown in RPMI1640 medium in absence of antileishmanial agents. The trend was similar for MIs. This observation was similar to that by Wabwoba et al. (2010), who observed that the IRs of amphotericin B and pentostam at $100 \mu \mathrm{g} / \mathrm{ml}$ were $9.0 \%$ and $11 \%$, respectively. In this study, however, although the difference between MI for amphotericin B and pentostam at $50 \mu \mathrm{g} / \mathrm{ml}$ was not statistically significant, the in vitro efficacy of amphotericin $\mathrm{B}$ in suppressing the amastigotes multiplication was higher than that of pentostam.

\section{Conclusion}

The findings of this study have justified the claimed medicinal importance of Solanum nigrum as a remedy for various infections. It can be concluded that the crude extracts of S. nigrum possess considerable anti-leishmanial activity, especially against Leishmania major, which were used in this study. The plant may contain potent anti-parasitic compounds, effective in the treatment of Leishmania infections. However, further investigation needs to be conducted on pure compound isolation, toxicological studies and clinical trials so as to use the promising compounds as effective antileishmanial agents.

\section{Data availability}

Dataset 1. Raw data for absorbance values from MTT assay and subsequent calculation of $\mathrm{IC}_{50}$ values on Vero cells for extracts of Solanum nigrum from Kisii and controls. For sorted raw absorbance data, columns 3, 6, 9 and 12 contain untreated cells; wells A1, A2, A4, A5, A7, A8, A10, A11, B1, B2, B4, B5, B7, B8, B10 and B11 contain medium only. Rows C-H contain indicated test samples, with extract concentrations of $31.25,62.5,125,250 \mu \mathrm{g} / \mathrm{ml}, 500$ and $1000 \mu \mathrm{g} / \mathrm{ml}$, respectively, and control drug concentrations of $16.125,31.25,62.5,125$, 
250 and $500 \mu \mathrm{g} / \mathrm{ml}$, respectively. DOI: https://doi.org/10.5256/ f1000research.15826.d214921 (Mutoro et al., 2018).

Dataset 2. Raw data for absorbance values from MTT assay and subsequent calculation of $\mathrm{IC}_{50}$ values (on Vero cells) for extracts of Solanum nigrum from Bungoma. For sorted raw absorbance data, columns 3, 6, 9 and 12 contain untreated cells; wells A1, A2, A4, A5, A7, A8, A10, A11, B1, B2, B4, B5, B7, B8, B10 and B11 contain medium only. Rows C-H contain test samples, with extract concentrations of $31.25,62.5,125$, 250, 500 and $1000 \mu \mathrm{g} / \mathrm{ml}$, respectively. DOI: https://doi.org/ 10.5256/f1000research.15826.d214922 (Mutoro et al., 2018).

Dataset 3. Raw data for absorbance values from MTT assay and subsequent calculation of $\mathrm{IC}_{50}$ values (on promastigotes) for extracts of Solanum nigrum from Kisii and controls. For sorted raw absorbance data, columns 3, 6, 9 and 12 contain untreated cells; wells A1, A2, A4, A5, A7, A8, A10, A11, B1, B2, B4, B5, B7, B8, B10 and B11 contain medium only. Rows C-H contain test samples, with extract concentrations of 62.5 , $125,250,500,1000$ and $2000 \mu \mathrm{g} / \mathrm{ml}$, respectively $\mathrm{C}$ to $\mathrm{H}$ for extract samples and 16.125, 31.25, 62.5, 125, 250 and $500 \mu \mathrm{g} / \mathrm{ml}$, respectively, for standard drugs. DOI: https://doi.org/10.5256/ f1000research.15826.d214923 (Mutoro et al., 2018).

Dataset 4. Raw data for absorbance values from MTT assay and subsequent calculation of $\mathrm{IC}_{50}$ values (on promastigotes) for extracts ofSolanum nigrum from Bungoma. For sorted raw absorbance data, columns 3, 6, 9 and 12 contain untreated cells; wells A1, A2, A4, A5, A7, A8, A10, A11, B1, B2, B4, B5, B7, B8, B10 and B11 contain medium only. Rows C-H contain test samples, with extract concentrations of $62.5,125,250,500$, 1000 and $2000 \mu \mathrm{g} / \mathrm{ml}$, respectively. DOI: https://doi.org/10.5256/ f1000research.15826.d214924 (Mutoro et al., 2018).

Dataset 5. Anti-amastigote (macrophage) assays. DOI: https:// doi.org/10.5256/f1000research.15826.d214929 (Mutoro et al., 2018).

Grant information

The author(s) declared that no grants were involved in supporting this work.
Abbas K, Niaz U, Hussain T, et al.: Antimicrobial activity of fruits of Solanum nigrum and Solanum xanthocarpum. Acta Pol Pharm. 2014; 71(3): 415-421. PubMed Abstract

Abreu Miranda M, Tiossi RF, da silva MR, et al.: In vitro leishmanicidal and cytotoxic activities of the glycoalkaloids from Solanum lycocarpum (Solanaceae) fruits. Chem Biodivers. 2013; 10(4): 642-648.

PubMed Abstract | Publisher Full Text

Ashwani K, Sagwal S, Rani S: An updated review of molecular genetics, phytochemistry and pharmacology of black nightshades (Solanum nigrum). Int J Pharm Res Sci. 2012; 3(9): 2956-2977.

Publisher Full Text

Barrett MP, Fairlamb AH: The biochemical basis of arsenical-diamidine crossresistance in African trypanosomes. Parasitol Today. 1999; 15(4): 136-140. PubMed Abstract | Publisher Full Text

Berman JD, Lee LS: Activity of antileishmanial agents against amastigotes in human monocyte-derived macrophages and in mouse peritoneal macrophages. J Parasitol. 1984; 70(2): 220-225.

PubMed Abstract | Publisher Full Text

Berman JD, Wayler DJ: An in vitro model for investigation of chemotherapeutic agents in leishmaniasis. J Infect Dis. 1980; 142(1): 83-86.

PubMed Abstract | Publisher Full Text

Cock IE: Antimicrobial activity of Callistemon citrinus and Callistemon salignus methanolic extracts. Pharmacognosy Communications. 2012; 2(3): 50-57. Publisher Full Text

Das JKL, Prasad SR, Mitra SK: Evaluation of Liv.52 DS tablet as hepatoprotective agent in prophy with statin therapy. Medical Update. 2007; 15: 31-36. Reference Source

Delahaye C, Rainford L, Nicholson A, et al.: Antibacterial and antifungal analysis of crude extracts from leaves of Callistemon viminalis. Journal of Medical and Biological Sciences. 2009; 3(1): ISSN 1934-7189.

Reference Source

Delorenzi JC, Attias M, Gattas CR, et al: Antileishmanial activity of an indole alkaloid from Peschiera australis. Antimicrob Agents Chemother. 2001; 45(5): 1349-1354.

PubMed Abstract | Publisher Full Text | Free Full Text

Desjeux P: Leishmania and HIV in Gridlock. Document WHO/CTD/LEISH/98.23. Geneva: World Health Organization. 1998.

Reference Source

Dujardin JC, Campino L, Cañavate C, et al:: Spread of vector-borne diseases and neglect of Leishmaniasis, Europe. Emerg Infect Dis. 2008; 14(7): 1013-8. PubMed Abstract | Publisher Full Text | Free Full Text
Fairlamb AH: Chemotherapy of human African trypanosomiasis: current and future prospects. Trends Parasitol. 2003; 19(11): 488-94.

PubMed Abstract | Publisher Full Text

Estevez Y, Castillo D, Pisango MT, et al:: Evaluation of the leishmanicidal activity of plants used by Peruvian Chayahuita ethnic group. J Ethnopharmacol. 2007; 114(2): 254-259.

PubMed Abstract | Publisher Full Text

Filho VC, Meyre-Silva C, Niero R, et al.: Evaluation of antileishmanial activity of selected brazilian plants and identification of the active principles. Evid Based Complement Alternat Med. 2013; 2013: 265025.

PubMed Abstract | Publisher Full Text | Free Full Text

Glossman-Mitnik D: CHIH-DFT Determination of the molecular structure and infrared and ultraviolet spectra of gamma-solanine. Spectrochim Acta A Mol Biomol Spectrosc. 2007; 66(1): 208-211.

PubMed Abstract | Publisher Full Text

Hendricks L, Wright N: Diagnosis of cutaneous leishmaniasis by in vitro cultivation of saline aspirates in Schneider's Drosophila Medium. Am J Trop Med Hyg. 1979; 28(6): 962-964

PubMed Abstract | Publisher Full Text

Hubert DJ, Céline N, Michel N, et al:: In vitro leishmanicidal activity of some

Cameroonian medicinal plants. Exp Parasitol. 2013; 134(3): 304-308.

PubMed Abstract | Publisher Full Text

Jain $\mathrm{R}$, Sharma A, Gupta S, et al:: Solanum nigrum: current perspectives on therapeutic properties. Altern Med Rev. 2011; 16(1): 78-85.

PubMed Abstract

Jumba BN, Anjili CO, Makwali J, et al.: Evaluation of leishmanicidal activity and cytotoxicity of Ricinus communis and Azadirachta indica extracts from western Kenya: in vitro and in vivo assays. BMC Res Notes. 2015; 8: 650.

PubMed Abstract | Publisher Full Text | Free Full Text

Khademvatan S, Gharavi MJ, Rahim F, et al.: Miltefosine-induced apoptotic cell death on Leishmania major and L. tropica strains. Korean J Parasitol. 2011; 49(1): 17-23.

PubMed Abstract | Publisher Full Text | Free Full Text

Kimber C, Evans D, Robinson B, et al:: Control of yeast contamination with 5-fluorocytosine in the in vitro cultivation of Leishmania spp. Ann Trop Med Parasitol. 1981; 75(4): 453-454.

PubMed Abstract | Publisher Full Tex

Kinuthia GK, Kabiru EW, Gikonyo NK, et al:: In vitro Activity of aqueous and methanol extracts of Callistemon citrinus (Family Myrtaceae) against Leishmania major. Afr J Health Sci. 2014; 27(2): 118-133.

Reference Source 
Laban LT, Anjili CO, Mutiso JM, et al.: Experimental therapeutic studies of Solanum aculeastrum Dunal. on Leishmania major infection in BALB/c mice. Iran J Basic Med Sci. 2015; 18(1): 64-71.

PubMed Abstract | Publisher Full Text | Free Full Text

Makwali JA, Wanjala FME, Ingonga J, et al:: In vitro Studies on the antileishmanial activity of herbicides and plant extracts against Leishmania major parasites. Res J Med Plants. 2015; 9(3): 90-104.

Publisher Full Text

McClure CD, Noland LL, Zatyrka SA: Antileishmanial properties of Allium sativum extracts and derivatives. Acta Horticulature. 1996; 426: 183-191. 14. Publisher Full Text

Mekonnen $\mathrm{Y}$, Yardley V, Rock $\mathrm{P}$, et al.: In vitro antitrypanosomal activity of Moringa stenopetala leaves and roots. Phytother Res. 1999; 13(6): 538-539. PubMed Abstract | Publisher Full Text

Mishra BB, Gour JK, Kishore N, et al.: An antileishmanial prenyloxynaphthoquinone from roots of Plumbago zeylanica. Nat Prod Res. 2013; 27(4-5): 480-485.

PubMed Abstract | Publisher Full Text

Mueller LA, Solo TH, Taylor N, et al.: The SOL Genomics Network: a comparative resource for

1310-1317.

PubMed Abstract | Publisher Full Text | Free Full Text

Musto M, Potenza G, Cellini F: Inhibition of Penicillium digitatum by a crude extract from Solanum nigrum leaves. Biotechnol Agron Soc Environ. 2014; 18(2): 174-180.

Reference Source

Mutoro CN, Kinyua JK, Ng'ang'a JK, et al.: Dataset 1 in: In vitro study of the efficacy of Solanum nigrum against Leishmania major. F1000Research. 2018. http://www.doi.org/10.5256/f1000research.15826.d214921

Mutoro CN, Kinyua JK, Ng'ang'a JK, et al.: Dataset 2 in: In vitro study of the efficacy of Solanum nigrum against Leishmania major. F1000Research. 2018. http://www.doi.org/10.5256/f1000research.15826.d214922

Mutoro CN, Kinyua JK, Ng'ang'a JK, et al.: Dataset 3 in: In vitro study of the efficacy of Solanum nigrum against Leishmania major. F1000Research. 2018. http://www.doi.org/10.5256/f1000research.15826.d214923

Mutoro CN, Kinyua JK, Ng'ang'a JK, et al.: Dataset 4 in: In vitro study of the efficacy of Solanum nigrum against Leishmania major. F1000Research. 2018. http://www.doi.org/10.5256/f1000research.15826.d214924
Mutoro CN, Kinyua JK, Ng'ang'a JK, et al.: Dataset 5 in: In vitro study of the efficacy of Solanum nigrum against Leishmania major. F1000Research. 2018. http://www.doi.org/10.5256/f1000research.15826.d214929

Ndeti CM, Kituyi C, Ndirangu M, et al:: Efficacy of combination therapy using extracts of Aloe secundiflora Eng I. and Callistemon citrinus William C. in Leishmania major infected BALB/c mice. East Afr Med J. 2016; 93(3): 127-134. Reference Source

Njau VN, Maina ENM, Anjili CO, et al.: Phytochemical analysis of Carissa edulis against Leishmania major. African Journal of Pharmacology and Therapeutics. 2016; 5(4): 253-262

Reference Source

Oketch GBA, Irungu LW, Anjili CO, et al:: In vitro activity of the total aqueous ethanol leaf extracts of Ricinus communis on Leishmania major promastigotes. Kenya Journal of Sciences, Series A\& B. Special Edition. 2006;

1(1): $1-4$

Reference Source

Santos DO, Coutinho CE, Madeira MF, et al.: Leishmaniasis treatment--a challenge that remains: a review. Parasitol Res. 2008; 103(1): 1-10.

PubMed Abstract | Publisher Full Text

Schlein Y, Jacobson RL, Müller GC: Sand fly feeding on noxious plants: a potential method for the control of leishmaniasis. Am J Trop Med Hyg. 2001; 65(4): 300-303.

PubMed Abstract | Publisher Full Text

Shen T, Li GH, Wang XN, et al:: The genus Commiphora: a review of its traditional uses, phytochemistry and pharmacology. J Ethnopharmacol. 2012; 142(2): 319-330.

PubMed Abstract | Publisher Full Text

Son YO, Kim J, Lim JC, et al.: Ripe fruit of Solanum nigrum L. inhibits cell growth and induces apoptosis in MCF-7 cells. Food Chem Toxicol. 2003; 41(10): 1421-1428.

PubMed Abstract | Publisher Full Text

Stuart K, Brun R, Croft S, et al.: Kinetoplastids: related protozoan pathogens, different diseases. J Clin Invest. 2008; 118(4): 1301-1310.

PubMed Abstract | Publisher Full Text | Free Full Text

Wabwoba BW, Anjili CO, Ngeiywa MM, et al.: Experimental chemotherapy with Allium sativum (Liliaceae) methanolic extract in rodents infected with Leishmania major and Leishmania donovani. J Vector Borne Dis. 2010; 47(3): 160-167.

PubMed Abstract 


\section{Open Peer Review}

\section{Current Peer Review Status: ? $\mathrm{X}$}

\section{Version 1}

Reviewer Report 05 November 2018

https://doi.org/10.5256/f1000research.17274.r39674

(C) 2018 Singh S et al. This is an open access peer review report distributed under the terms of the Creative Commons Attribution License, which permits unrestricted use, distribution, and reproduction in any medium, provided the original work is properly cited.

\section{Sarman Singh}

Department of Laboratory Medicine, All India Institute of Medical Sciences, New Delhi, India

\section{Saumya Srivastava}

All India Institute of Medical Sciences, New Delhi, India

Comments:

Abstract:

Abstract should be rewritten even the IC 50 of standard drugs are not matching with the result section of the manuscript.

Keywords: Leishmania major and Solanum nigrum should be in italics throughout the manuscript; eg: Leishmania major and Solanum nigrum

Methods:

No subheading or paragraph describes the maintenance of cell lines which is being used for cytotoxicity. This is important information which is missing. Please add these details.

Mice and Leishmania parasites:

We wonder that the parasites are being cultured in Drosophila medium instead of M199 or RPMI. Drosophila medium is often used to achieve the fast primary isolation rather than maintenance. The M199 and RPMI media are far better for the maintenance of the parasites.

Preparation of the stock solution of test extracts:

The stock solution of the extracts in the culture medium should be prepared freshly immediate before the use. It should not be stored for later use as it may change the $\mathrm{pH}$ value of the medium which can hamper the activity of the extracts. It also can lead to the high rate of contamination. Furthermore, if at all, it should be stored only in the solvent not in the medium. cytotoxicity assay using Vero cells to determine IC 50:

This paragraph needs to be rewritten. There are no details of counting of the cells. 
In the beginning of the manuscript, the authors mention volume of the suspension of cells from which $100 \mathrm{ul}$ of cells were directly used and finally declared it as $1 \times 106$ cells per ml. To our minds the centrifugation and counting of the cells with its procedure is extremely important to claim any activity of anti leishmanial compounds. Otherwise results are difficult to be reproduced.

It is also not clear, how the authors could test 6 dilutions of 4 extracts?. As per the description of plate designing the cells were plated only in two wells of A-H row? (as mentioned in line no 11 in the above subheading). This totals to only 16 . It is serious concern for this reviewer.

Again authors have not mentioned the time duration of incubation before aspirating out the MEM medium. It is the required time for the adhering to the solid phase. Otherwise cell will also be aspirated off with the medium, and making the study claims untenable.

Again the same section authors have no-where mentioned the standard drugs and concentrations thereof, if at all used for the assay. But in the result section the results of the standard drugs are mentioned on the top. How come?

Authors should also mention the exact timing of incubation performed by them after MTT addition , not 2-4 hrs, which is very arbitrary and not acceptable.

Evaluation of MIC \& Evaluation of IC 50 and anti-promastigote assay.

A big question is, if the authors performed two different tests to evaluate MIC and IC 50 value individually? If not then the heading can be merged as Antipromastigote assay to evaluate the IC 50 and MIC of the Test extracts. Evaluation of IC 50 and antipromastigote assay.

What does authors mean by serial dilutions of $2.0 \times 103,1.0 \times 103,5.0 \times 102,2.5 \times 102,1.25 \times 102$, and $6.25 \times 101$ ? The dilutions are written in different manner, either as log or serial, but not like this. if these are extract's dilutions than there should be uniformity in the unit representation of the concentration of the drugs for all assays.

Somewhere it is $\mathrm{mg} / \mathrm{ml}$ and somewhere its $\mathrm{ug} / \mathrm{ml}$ for the same drugs.

Again there is no discussion of standard drugs under this subheading.

Authors should mention method of visual reading by microscopic observation (if done) before mentioning the survival comparison.

Anti-amastigote assay:

The amount of sterile cold PBS injected in the peritoneum seems very low in volume.10 ul will go no where and no one can withdraw it back. write carefully.

What was the ratio of macrophage and promastigotes used for this assay. No counting and ratio is mentioned.

Were $4 \mathrm{hrs}$ sufficient for the infection incubation as the promastigotes takes at least 8-12 hrs for engulfment to Maximum $24 \mathrm{hrs}$. in the manuscript again the plate was incubated for $24 \mathrm{hrs}$ but after the washing step. After reading their protocol, we really cannot believe the results, if these 
are genuine. And what was the need of

second incubation. In this section the concentration of plant extracts used are missing.

Authors must have mentioned the magnification $(x)$ used for the microscopic observation.

Amastigotes are only possible to visualize at $1000 \times$ magnification with oil which is not possible in 24 well plate directly. We can't understand how authors could count the amastigotes.

Statistical analysis:

All the experiments could have been performed in duplicate wells in the same assay. And also could have been repeated thrice for mean and SD Value, which is not done in cytotoxic and antipromastigote assays mentioned in this manuscript. Culture was done in duplicate only in antiamastigote assay, for which $p$ value can be calculated by simple way. ANOVA and Tukey's Test is not needed.

Results:

As there are so many flaws in methodology section there is no meaning of evaluating-the results. At every step the results must match with the methodology used. This is missing in this otherwise poorly written paper.

Even the concentration unit is not uniform. The IC 50 value of standard drugs are not even appropriate .

Figure 1 is not even clear to visualize the macrophages. How come author counted the amastigotes?

Recommendation: The authors are encouraged to go through a recent publication by Srivastava et al, $2017^{1}$ and resubmit the manuscript as fresh.

\section{References}

1. Srivastava S, Mishra J, Gupta A, Singh A, et al.: Laboratory confirmed miltefosine resistant cases of visceral leishmaniasis from India. Parasites \& Vectors. 2017; 10 (1). Publisher Full Text

Is the work clearly and accurately presented and does it cite the current literature? No

Is the study design appropriate and is the work technically sound? No

Are sufficient details of methods and analysis provided to allow replication by others? No

If applicable, is the statistical analysis and its interpretation appropriate? Not applicable

Are all the source data underlying the results available to ensure full reproducibility? Partly 
Are the conclusions drawn adequately supported by the results?

No

Competing Interests: No competing interests were disclosed.

We confirm that we have read this submission and believe that we have an appropriate level of expertise to state that we do not consider it to be of an acceptable scientific standard, for reasons outlined above.

Reviewer Report 31 August 2018

https://doi.org/10.5256/f1000research.17274.r37485

(C) 2018 Kasili S et al. This is an open access peer review report distributed under the terms of the Creative Commons Attribution License, which permits unrestricted use, distribution, and reproduction in any medium, provided the original work is properly cited.

Sichangi Kasili

Department of Biology, South Eastern Kenya University, Kitui, Kenya

Helen Kutima

Jomokenyatta University, Juja, Kenya

Abstract

- Grammar: "Parasites cause" not "parasites causes".

There are currently inadequate therapeutic interventions to manage this endemic tropical disease, transmitted mainly by phlebotomine sandflies hence there is need to develop affordable and effective therapeutic measures.

The current study sought to determine the in vitro efficacy of Solanum nigrum methanolic and aqueous plant extracts on Leishmania major parasites.

When making reference to numbers use digit if more than ten i.e. "three" and not " 3 ".

There should be an indication of the country where the study was contacted, how the plants for plant extracts were collected and the animal models used.

There is no indication of how the results of the study were analyzed statistically.

Methanolic extract of $S$. nigrum from Kisii seemed to be more efficacious in vitro since it knocked out the promastigotes at a lower MIC level $(0.5 \mathrm{mg} / \mathrm{ml})$ when compared to all other extracts whose effective MIC level was $\geq 1 \mathrm{mg} / \mathrm{ml}$.

Last sentence needs rephrasing.

Introduction

- Grammar, especially some words lacking in connectives i.e. in first line the word "by" is missing between "caused" and "Leishmania".

- Leishmaniasis represents an important health and socioeconomic problem in 88 countries around the world, where this disease is endemic according to a study by (Dujardin et al. $2008^{1}$ ).

There are long sentences which need to be broken to make sense. 
There is need for the authors to demonstrate the need for investigating the plants they used given that a number of studies show promising results. What was different with the plant?

Methods

The mice were handled in accordance with the regulations set by the Animal Care and Use Committee at KEMRI.

Statistical analyses should be specifically in respect of the assays conducted rather than general presentation.

How were survival rates of $L$. major promatigotes analyzed?

Why did the authors not use same concentrations of the test extract and control drugs then increase concentrations of test extracts if required?

How was Tukeys test used?

Scientific names should be italicized in this section and the rest of the manuscript.

Remove repetitions of the methods in this section.

Titles of tables should not be combined with what should be footnotes i.e. table 1 and 3 .

Rework on table 2 for better presentation

Avoid use of abbreviation IRs, not standard.

Figure 1 not necessary.

Discussion

Avoid direct repetition of results in discussion i.e. most of paragraph 1.

Authors should insert the explanation for why there are differences in extracts after the relevant sentence.

What is the relevance of the second paragraph to the current study?

Discuss each section of the results separately and thoroughly by comparing with other studies, including own opinions and explanations.

References

Are the phrases in red font after each reference a journal requirement? If not delete.

Datasets sites should be removed from reference section.

\section{References}

1. Dujardin JC, Campino L, Cañavate C, Dedet JP, et al.: Spread of vector-borne diseases and neglect of Leishmaniasis, Europe.Emerg Infect Dis. 2008; 14 (7): 1013-8 PubMed Abstract |

Publisher Full Text

Is the work clearly and accurately presented and does it cite the current literature? Yes

Is the study design appropriate and is the work technically sound?

Yes

Are sufficient details of methods and analysis provided to allow replication by others? 


\section{Partly}

If applicable, is the statistical analysis and its interpretation appropriate? Yes

Are all the source data underlying the results available to ensure full reproducibility? Yes

Are the conclusions drawn adequately supported by the results?

Yes

Competing Interests: No competing interests were disclosed.

We confirm that we have read this submission and believe that we have an appropriate level of expertise to confirm that it is of an acceptable scientific standard, however we have significant reservations, as outlined above.

The benefits of publishing with F1000Research:

- Your article is published within days, with no editorial bias

- You can publish traditional articles, null/negative results, case reports, data notes and more

- The peer review process is transparent and collaborative

- Your article is indexed in PubMed after passing peer review

- Dedicated customer support at every stage

For pre-submission enquiries, contact research@f1000.com 